\title{
Development of a University Research Management Policy Applied to the Faculty of Dentistry.
}

\author{
Ramón Fuentes ${ }^{1,2^{*}}$; Constanza Farfán ${ }^{1}$
}

1. Dental School, Research Centre for Dental Sciences (CICO), Universidad de La Frontera, Temuco, Chile.

2. Department of Integral Adults Dentistry, Dental

School, Universidad de La Frontera, Temuco, Chile

* Corresponding author: Ramón Fuentes Fernández | Address: Av. Francisco Salazar 1145, Temuco,

Chile | Email: ramon.fuentes@ufrontera.cl

Work received on: 11/09/2020

Revised work: 20/11/2020

Approved for publication on 05/12/2020

\begin{abstract}
Universities are immersed in a globalized world with new knowledge and technologies. This requires to focus their objectives to meet society's demands. Advanced human capital has to be capable of strategic planning which is key to university development and must be aimed at educational excellence, quality of scientific research, and highlevel technology. These elements make possible the creation of efficient units capable of performing in increasingly demanding markets. The objective is to describe a policy strategy for university research management applied to the Faculty of Dentistry at the University of La Frontera. The development of this policy included a strategy based on the generation of a research environment through the creation of a Master's degree and the establishment of four pillars: recruitment and training in research of human resources, creation of research centers, creation, and implementation of research laboratories and collaboration with national bodies and foreign universities. This policy has succeeded in improving scientific production and publication quality, positioning the Faculty of Dentistry within the Universidad de La Frontera. We consider that the strategy presented can be applied in different faculties of Chilean Universities. For its application, technological and social advances and demands of the current times must be considered.
\end{abstract}

\section{KEY WORDS}

University research management; Dental research; Scientific production.

Int. J. Inter. Dent Vol. 14(2); 144-147, 2021.

\section{INTRODUCTION}

The contemporary university is amid multiple demands arising from various historical and social factors associated with the changes experienced in the last century ${ }^{(1)}$. Globalization, new knowledge, and technologies demand that universities focus their objectives on longterm goals to meet society's demands. For decades, attempts have been made to define universities' social responsibility; one definition by Howard Bowen ${ }^{(2)}$ states it as "the obligations of university managers to drive institutional policies, make decisions or follow lines of action that are desirable in terms of society's objectives and values". In this context, they have defined a set of essential roles for universities in the era of globalization. These roles are advanced human capital training, cutting-edge knowledge expansion, and the contribution to equality and territorial development. These are basic tasks that allow universities to respond to society's demands, strengthening the country's market competitiveness, its development, and increase job opportunities ${ }^{(3)}$.

In Latin America, universities are the main path to strengthen national scientific production. They have access to results achieved through innovation and development of scientific knowledge, as well as the infrastructure and qualified personnel needed to design and implement strategic guidelines on a national scale ${ }^{(4)}$. In 1997, UNESCO identified the relevance of developing research, communication, and new technologies in Latin American and Caribbean universities for the development of their societies, and proposed an academic program to manage new information and communication technologies to modernize university education in all its areas ${ }^{(5)}$. It is stated that the university educational excellence, as well as the high-level scientific and technological research, are key elements in facilitating the creation and implementation of productive units capable of performing in increasingly demanding markets ${ }^{(6)}$.

Universities have a relevant influence on society, supporting central and local governments in their interests of social and economic development. To achieve their different objectives, they require advanced human capital, capable of developing strategic plans. In 2000, Serna ${ }^{(7)}$ defined strategic planning as "the process in which decision-makers in an organization obtain, process, and analyze pertinent internal and external information to evaluate the institution's current situation and its level of competitiveness to anticipate and decide on the organization's future direction". Universities require trained personnel in charge of producing these plans. Currently, this function is fulfilled temporarily and rotationally by academics allocated for this work; however, it is more efficient if this function is performed by specialized, permanent professionals for long-term results.

The aim of this article is to describe a long-term university research policy strategy applied to the Faculty of Dentistry at the Universidad de La Frontera in order to improve the levels of scientific production and, after 10 years since the beginning of its implementation, its results and impact on scientific production and publication quality.

\section{METHOD}

A description of the implementation and development of the research policy was done from local documentation within the Faculty of Dentistry. The policy is composed of a strategy and four pillars that aim to improve the research production of the Faculty of Dentistry of Universidad de La Frontera. To assess its results, the increase in the number of research articles indexed in WoS, SciELO, and Scopus databases was recorded and reported as tables and graphics. The baseline was established in 2009 , the year the policy began to be implemented.

\section{RESULTS}

\section{- STRATEGY}

- The strategy was based on generating a research environment which was consolidated through the creation of a Master's degree in 2010.

\section{Master of Dentistry:}

Its objective is to train graduate professionals with competencies in the dental research area. Since its creation, measurable research 
indicators have improved, scientific publications in indexed journals among them. The master was accredited for six years, until December 2020, by the Chilean National Accreditation Commission (CNA).

The program consists of a core of academic staff with developed lines of research. Priority was given to studies on these established areas. Being a member of the core of academics in the Master of Dentistry program requires minimum compliance with the criteria stipulated by the $\mathrm{CNA}$, who make a distinction between the requirements for the members individually, and the faculty as a whole.

\section{Individual requirements by CNA include:}

- To have published 6 research papers in WoS, Scopus, or SciELO, a book chapter or a book with external referees and editorial committee, within the last 5 years.

- At least $50 \%$ of research publications as first or corresponding author.

\section{Faculty requirements:}

At least $60 \%$ of the academics have been principal investigator in a research project with internal or external competitive funding within the last 5 years.

\section{Projects with internal competitive funding must include:}

- Peer evaluation.

- Minimum duration of 2 years.

- Minimum budget of UF 200.

- To consider indexed project-related publications as a completion requirement.

Projects with external competitive funding can be from different institutions. They must meet conditions equivalent to those for internal funding, and they must be evaluated on an exceptional basis by the Health Sciences Committee. The most widely known external funding schemes by its acronym in Spanish are: FONDECYT (Fondo Nacional de Desarrollo Científico y Tecnológico), FONDEF (Fondo de Fomento al Desarrollo Científico y Tecnológico), FONIS (Fondo Nacional de Investiagción y Desarrollo en Salud), PIA (Programa de Investigación Asociativa), and CORFO (Corporación de Fomento de la Producción).

The lines of research offered at the Master's program are:

1.- Technology in biomaterials and regeneration of the stomatognathic system.

2.- Morphology, physiopathology, and development of the stomatognathic system.

3.- Evaluation of health technology in dentistry.

4.- Epidemiology, diagnosis, and treatment in oral and maxillofacial pathologies.

5.- Legal, anthropological, and forensic dentistry.

The master's creation positively affected the scientific production of the Faculty of Dentistry at the Universidad de La Frontera. Since its first cohort in 2010 up to the last cohort which graduated at the date of this publication (2018 cohort), the program has trained 51 professionals who have satisfactorily completed the program requirements, including a very important one, which is the scientific dissemination of knowledge gained in their thesis topics through a scientific publication of their research in an indexed journal in the Web of Science (WOS) database, or two articles submitted or published in indexed journals in the Scientific Electronic Library Online (SciELO) database or Scopus. From these 51 professionals trained since 2010, 68 scientific articles have been published (Figure 1), 66\% are indexed in WOS, $29.5 \%$ in SciELO, and $4.5 \%$ in Scopus. This represents a high level of research achieved through two main factors: a competent and committed faculty where researchers stay up-to-date, actively publish in their areas and possess the tools to supervise a thesis project effectively, together with students with experience and interest in research. This favors the development of the planned research and its publication.

This happens in juxtaposition to undergraduate courses theses, where the stimulation for studies to be published is lacking ${ }^{(8)}$. In undergraduate syllabi the competency of scientific development and research is part of the professional learning and, within the fields of dentistry and medicine, authors have stated that this training in scientific competencies must be accompanied by the process of scientific production and dissemination ${ }^{(8,9)}$, however, usually these research activities do not make any contribution to medicine other than to fulfill a requirement to get a grade in a course (10). Hence, they require the development of initiatives that lead to better results in the participation of undergraduate students in their theses.

Together with the strategy described, the increase in scientific productivity of the Faculty of Dentistry at the Universidad de La Frontera was also supported by the four fundamental pillars described next:

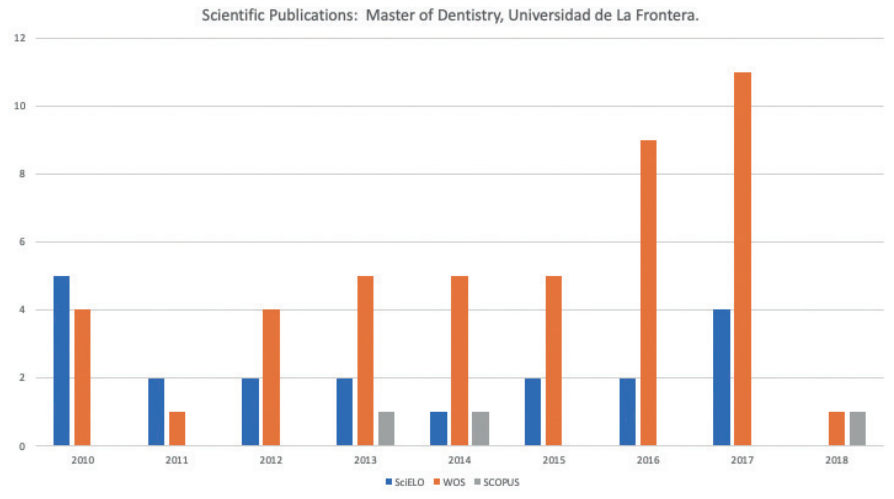

Figure 1. Indexed scientific publications since the first cohort (2010) of Master of Dentistry students. Scientific Electronic Library Online (SciELO); Medline database (PUBMED); Elsevier's abstract and citation database (SCOPUS).

\section{-PILLARS}

1) Hiring and training of human resources (HR) in research:

Training HR capable of meeting the demands of the advances in science and technology is a necessary process in universities. This HR must be incorporated as strategic elements and their work must be oriented towards achieving effectiveness and efficiency for high performance ${ }^{(11)}$. In the university context, the hiring of HR must be complemented with appropriate training, which carries a great responsibility for those in charge of hiring. These people must have comprehensive knowledge, solid pedagogical abilities, and the willingness to guide and support students ${ }^{(12)}$. The generational changes have become a challenge and demand that academics and their teaching strategies adapt to different working and learning styles.

To ensure their productivity in the university, HR qualified in research with complete graduate training and established productivity were hired. Special emphasis was placed on the lines of research that they developed before coming to the university, so they could continue developing them.

On the other hand, the undergraduate program is a breeding ground for future researchers. Due to the curricular reforms aimed at scientific training and research policies that give priority to the participation of undergraduate and graduate students in research, a scenario of collaboration has been established. This scenario has been highly significant to hire capable new HR to suitably develop a career in research and meet quality demands and scientific production. For students, this becomes an increasingly useful and valuable tool in their training that broadens their professional horizons and self-reliance in the development of research skills from early courses. Training qualified $\mathrm{HR}$ in research has been done by identifying graduates who have demonstrated research skills during their undergraduate education and with interest in improving in this area. After some years with an employment contract where they must demonstrate research skills, they are sponsored to undertake doctoral studies, mainly abroad.

Another important aspect that this strategy has developed is having support professionals available mainly for researchers who require them (i.e. biostatisticians, veterinarians, and bioengineers).

\section{2) Creation of Research Centers:}

The second pillar is the creation of research centers within the Faculty of Dentistry. This initiative was chosen because this organizational structure only requires approval by the faculty council and does not require funding. In addition, disciplinary development under departments has not been adequately regulated, thus, leadership in research within them is difficult because they function mainly as organizational units for administration and teaching.

Leaders in research groups were not imposed. Researchers were grouped by affinity and common research topics so that a natural leader would emerge among them. This had good results as lines of research were consolidated and strengthened. This gave researchers more academic freedom and autonomy in decision-making. In light of the success these centers have enjoyed (more than $90 \%$ of publications in the Faculty of Dentistry come from academics assigned to centers), funding was given to each of them. Later, an initiative was generated to give funding according to their productivity in terms of their scientific publications. The basic infrastructure was set up to implement the following research centers: 
- Research Center for Dental Sciences (CICO).

- Research Center in Public Health, Economics, and Oral Epidemiology (CIESPO).

- Research Center in Applied Morphology (CIMA).

- Research Center in Innovation in Clinical Dentistry (CIDIC).

- Research Center in Legal and Forensic Odontology (ClO).

\section{3) Creation and implementation of research laboratories:}

Together with the formation of the research centers, laboratories with the equipment needed to conduct high-level research were implemented. The aim of these laboratories was to support current and future lines of research in each center. Priority was given to invest in centers that have already established productivity. The members of the centers help to fund the supplies of each laboratory and in some cases complement equipment through the awarding of internal and external research projects. Thus, the following laboratories were formed: $\mathrm{CICO}$ Oral Physiology Laboratory; Endodontics Laboratory; Postulography Laboratory; Plastination Laboratory; Finite Elements Laboratory/ CIMA: 3D Imaging and Modeling Laboratory/ CIDIC: Experimental Clinical Imaging Laboratory/ CIO: Forensic Odontology Laboratory.

In addition, researchers can access major equipment at other university' facilities such as the Technological Scientific Nucleus in Bioresources (BIOREN-UFRO) and the Center of Excellence in Morphological and Surgical Studies (CeMyQ).

\section{4) Cooperation with National and Foreign Universities:}

Internationalization today represents one of the strategic axes that guide institutional policy and engages the university with the current challenges in higher education and the advance of science and technology. The integration process is described as an international and intercultural dimension to the university's teaching, research, and service functions ${ }^{(13)}$. There is a variety of factors that favor this internationalization. In 2002, Knight(14) wrote that trade liberalization is interpreted as the elimination of barriers to promote greater crossborder movement of education services. Similarly, Didou Aupetit ${ }^{(15)}$ stated in 2007 that although the international nature of certain university activities goes back a long time, the interest in promoting a policy of internationalization has been emerging for little more than a decade. Several authors agree that university internationalization emerged in the $90 \mathrm{~s}$ and the explanation for this phenomenon is partly due to globalization ${ }^{(3)}$. This is has become a responsibility for university managers since university internationalization has gained strength and its scope has been broadened lately, making it a priority in higher education policies.

Internationalization encompasses different activities within the university environment that involve the entire community. International cooperation is developed through activities undertaken between institutions of higher learning that involve association and collaboration in the areas of institutional policy and management, academic training, research, outreach, and connecting to the goals of institutional strengthening, the improvement of teaching quality, and the increase and transfer of scientific and technological knowledge ${ }^{(16)}$. It could be said that international cooperation helps to improve research and teaching standards, giving rise to competitiveness, and that, developing certain visible and attractive activities not only makes us more internationalized as an institution but more visible and attractive as well.

This fourth pillar fulfills the aforementioned characteristics related to international cooperation. This pillar consists of cooperation with national and foreign universities through different mechanisms. These include:

1.- Projects financed by National Research and Development Agency of Chile (ANID) for short-term fellowships for six professors-researchers from foreign universities, who aided in the development of specific lines of research during their stay.

2.- Collaboration agreements with national and foreign universities that provide a framework for academic exchange.

3.- Short-term fellowships at foreign universities for Faculty researchers. Thus, spaces were created which would later be used for doctoral studies funded mainly by Becas Chile.

4.- Internal and external project funding for short-term fellowships by Faculty researchers at foreign institutions. Also allowing foreign researchers to come to this institution.

These, together with the previous initiatives, has led to an increase not only in the number of publications, but also in their quality, regarding their indexing, impact factor, and quartile. In addition, this has allowed the creation of international agreements in a fluid and effective way.

Each pillar is inter-related. The strategy to create a research environment that serves as a reservoir of professionals interested in research through the creation of a master's degree is complemented by all these pillars: the training and hiring of $\mathrm{HR}$ since students are potential HR trained to fulfill research functions. The creation of research centers and research laboratories where the master of Dentistry develop their theses, and finally, the fourth pillar, which consists of national and international cooperation, is present in the Master's as the students can attend courses at national and international universities and are required to disseminate the knowledge gained in national and international papers. For the success of this policy, each of the described pillars must be in constant interaction.

From the beginning of the implementation of the previously described university management policy, its positive results have been confirmed. Figure 2 shows the increase in both the number of publications and indexing. It should be emphasized that since 2014 the number of publications has been steady, which indicates that the implementation of the policy produces stable and permanent results over time.

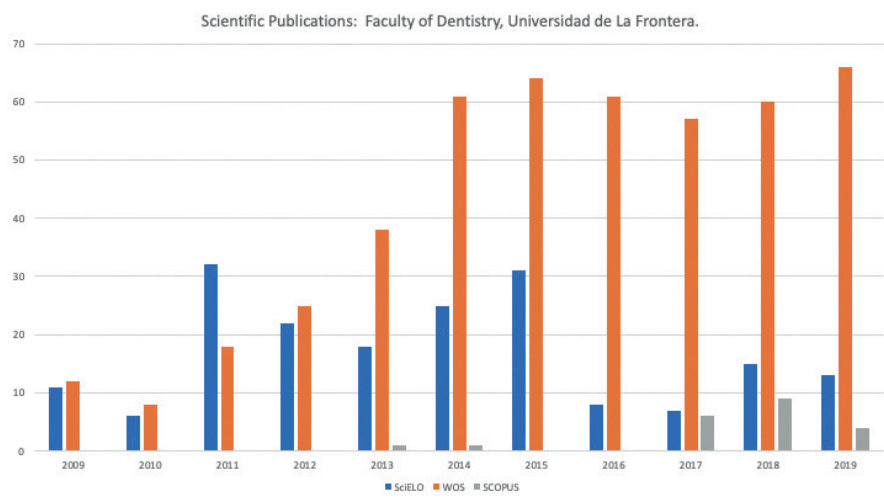

Figure 2. Scientific production of the Faculty of Dentistry, Universidad de La Frontera, period of 10 years, since the implementation of the research management policy. Scientific Electronic Library Online (SciELO); Medline database (PUBMED); Elsevier's abstract and citation database (SCOPUS).

\section{DISCUSSION}

Strategic planning is considered a basic and essential process for university management. In Latin America, this process has been complex for traditional universities. At the beginning of the new millennium, most universities in the region lacked an effective administrative organization and a lack of knowledge of the importance of academic and scientific administration ${ }^{(1)}$. The causes of this have been described, and include the low level of training of teachers with doctoral degrees, the poor articulation between government, science, and technology entities, and universities, and insufficient research activities in most Latin American universities ${ }^{(17)}$

Over time, and due to the advance of technological development and the demands of post-industrial society, universities have acquired a new dimension in their functions and must apply the knowledge they produce as a tool to enable this social development at the national and regional levels. This has led to the need for changes and reforms in higher education research systems and technological management ${ }^{(4)}$. In this context, the planning and reforms that arise, must contemplate a set of integrated processes, be capable of systematizing actions to achieve the proposed goals in a specific context. The research management model described in this article had a dynamic and flexible activity. It was a methodological process that required time and continuous analysis for its development and achievement of results. There are articles in the literature describing the basic steps for achieving strategic planning in the university setting; however, no studies oriented to university management of organizational structures in the health area were found. We consider that the strategy presented here can be applied in different faculties of Chilean Universities. For its application, the technological advances and current social development must always be considered, together with having a continuous analysis and monitoring of the objectives proposed and being willing to modify them according to the local context and social demands.

\section{CONCLUSIONS}

The establishment and development of the management policy to generate an increase in scientific production in the Faculty of Dentistry required time for its planning, experience gain by the manager, and constant improvement during its gradual establishment. 
The creation of the research centers helped to group and consolidate the lines of research developed within the Faculty of Dentistry. The different areas were strengthened through the hiring of HR, the creation of research laboratories, and collaboration with national and international universities. The results were scientific publications by the five research centers, which currently represent more than $90 \%$ of the total publications of the Faculty of Dentistry. Consequently, there is evidence of a significant increase in the awarding of projects by external funding bodies.

The development of the research management policy described had successful results and significantly improved the scientific production of the Faculty of Dentistry. This produced research HR, increased the creation of knowledge and also improved the quality of publications, strengthened undergraduate research, and the international mobility of professionals and students. All this made the faculty more visible, increasing its research competitiveness within the university and the region.

\section{CLINICAL RELEVANCE}

The following article describes a management policy in applied university research at the Faculty of Dentistry of the University of La Frontera for ten years. An analysis of the pillars that shaped it and its results in terms of scientific productivity achieved is made. We believe it is relevant to expose a strategy of university management linked to research that can be applied in a transversal way in the different faculties of Chilean universities. For its application, technological advances, the social development of the time, the local context and the current social demands should be considered.

\section{CONFLICT OF INTEREST}

The authors declare that there is no conflict of interest.

\section{FUNDING SOURCE}

The authors received no specific funding for this work.

\section{References}

1. Tunnermann C. Universidad y Sociedad: Balance histórico y perspectivas desde Latinoamérica. Caracas: Editorial Hispamer; 2000.

2. Bowen $H$. Social responsibilities of the businessman. New York: Harper \& Brothers;1953.

3. Rodríguez-Ponce E. El rol de las universidades en la sociedad del conocimiento y en la era de la globalización: evidencia desde chile. INCI. 2009;34(11):822-29. 4. Royero J. Gestión de sistemas de investigación universitaria en América Latina. RIE. 2011;355:109-33.

5. Gonzalez L, Ayarza H. Calidad, evaluación institucional y acreditación en la educación superior en la región Latinoamericana y del Caribe. Conferencia regional CRESALC/UNESCO; noviembre 1996. La Habana.

6. Clemenza C, Ferrer J, Araujo R. La Investigación universitaria como vía de fortalecimiento de la relación Universidad-Sector Productivo. Caso: La Universidad del Zulia. Multiciencias. 2004;4(2):1-15.

7. Serna H. Gerencia Estratégica. Caracas: Ediciones Global S.A.; 2000.

8. Castro-Rodríguez Y. Factores que contribuyen en la producción científica estudiantil. El caso de Odontología en la Universidad Nacional Mayor de San Marcos, Perú. Educ Med. 2019;20(1):49-58.

9. Velásquez JD. Importancia de la publicación científica en el pregrado de medicina. Rev Hips Cienc Salud. 2016;2(2):184-5.

10. Ortega-Loubon C, Zúñiga-Cisneros J, Yau A, Castro F, BarríaCastro JM, Lalyre A, et al. Producción científica de los estudiantes de medicina de la Universidad de Panamá. Arch Med. 2013;9(3):1-9.
11. Agudelo M, Alveiro C, Saavedra B, Ramiro M. El recurso humano como elemento fundamental para la gestión de calidad y la competitividad organizacional. VDF. 2016;20(2):1-20.

12. Szilagyi J, Szecsi T. Transforming teacher education in Hungary, competencies for elementary teachers. Child Educ. 2011;85(5):327-31.

13. Knight J. Internationalization: Elements and Checkpoints. Monografía investigativa. Ottawa:CBIE;1994.

14. Knight J. Trade in higher education services: The implications of GATS. Canada: The observatory on borderless higher education; mayo 2002.

15. Didou A, Sylvie. La internacionalización de la educación superior en América Latina: oportunidades y desafíos. Conferencia Universidad Nacional de Córdoba; agosto 2007. Córdova.

16. Sebastián J. Cooperación e internacionalización de las universidades. Buenos Aires: Biblos;2004

17. Lemasson J, Chiappe M. La investigación universitaria en América Latina Caracas: Ediciones IESALC/UNESCO;1999. 